\title{
Gold Nanoparticles: Their Application as Antimicrobial Agents and Vehicles of Gene Delivery
}

\author{
Surekha Kundu* \\ Department of Botany, University of Calcutta, India \\ Submission: June 04, 2017; Published: August 09, 2017 \\ *Corresponding author: Surekha Kundu, Department of Botany, University of Calcutta, India, Fax: 011-91-33-2461-4849; \\ Tel: 011-91-33-2461-4688; Email: surekha_kundu@yahoo.com
}

\begin{abstract}
Research work on the synthesis and application of gold nanoparticles are areas of great interest in modern science. Gold nanoparticles can be synthesized through physico-chemical means or through utilization of biological extracts. Gold nanoparticles have antimicrobial activities that often depend on the shape and sizes of the particles. The mechanism behind antimicrobial properties of gold nanoparticles is mainly through causing pores in the membrane and upon entering the microbe, these bind to internal structures causing stress-related injuries such as production of ROS Another major application of gold nanoparticles is that these can be used for gene delivery. Capping of the nanoparticles with various coating materials is an essential step to provide sites for attachment of the DNA to be delivered. Moreover capping enhances uptake and retention of the gold nanoparticles by cells during gene delivery. Gene delivery properties again depend on the capping material, the shape and sizes of the nanoparticles. The potential of nanoparticles as antimicrobial agents and vehicles of gene delivery is discussed.
\end{abstract}

Keywords: Gold nanoparticles (Gnps); Antimicrobial; Capping; Gene delivery; Cytotoxicity; Photoluminescent; Transfection; Biomedical; Cancer

\section{Introduction}

The synthesis and biomedical application of noble metal nanoparticles specially gold nanoparticles (GNPs) is a promising field of research and has garnered the attention of vast groups of researchers. Bulk metallic gold $(\mathrm{Au})$ is known to be chemically inert. However, when the size of gold is reduced to nanometer ranges it starts to show diverse biological properties [1]. GNPs find application in many fields, ranging from electronicsto agriculture, biomedicines and pharmacy [2].

Metallic nanoparticles, especially GNPs, can be relatively easily prepared, have high gene transfection efficiency [3], and their surfaces can be customised by chemical modifications [4] allowing effective attachment of payloads through various means. The tailored ability to ensure cellular uptake with controlled release of the drug to specific cell target, significant stability, bioinertness with notoxicity of gold have made GNPs a popular candidate for biomedical applications such as biosensors, drug delivery for cancer chemotherapy and radiotherapy $[5,6]$.

Physico/chemical mode of synthesis of gold nanoparticles versus synthesis of nanoparticles using biological agents

Chemical and physical syntheses of NP are common. However, biological synthesis is more acceptable for being eco-friendly and simple [7]. It allows the controlled synthesis of nanoparticles with definite size and shape [8]. Due to their versatility in biological functionalization, biological nanoparticles are finding excellent applications in the field of medicine and drug delivery $[2,7]$.

Biosynthesis of nanoparticles using microorganisms like bacteria [9], actinomycetes [10], algae [11] and fungi like yeast [12], Aspergillus fumigatus [13], Phanerochaete chrysoporium [14], Macrophomina phaseolina [2] have been investigated. Approaches using plant extracts [15] and plant parts are also coming forth $[8,16]$. Fungi are drawing great attention in this regard as they are excellent secretor of extracellular enzymes, easy to scale up both in small and large scale production. Furthermore, the large surface area of the mycelia and downstream processing would be much simpler using fungi [2]. Extra-cellular synthesis of GNPs by green routes using edible mushrooms is relatively new addition in this context ensuring less toxic chemicals adhering to the nanoparticles $[5,6,17,18]$.

Antibacterial properties of gold nanoparticles with special reference to size and shape

Although gold nanoaparticles are not as strong a antimicrobial agent as silver nanoparticles, GNPs have been 
reported to possess both antimicrobial activities [19] and antifungal activities [20,21]. GNPs with antibacterial have also emerged as an alternative to high-dose administration of antibiotics and proven their effectiveness against infectious diseases including antibiotic-resistant ones [6]. NP toxicity and antibacterial mechanism mainly depends on surface modification, intrinsic properties, and the bacterial species tested. GNPs of smaller dimensions are more likely to penetrate the bacterial cells and cause cell damage, followed by death [22]. Antibacterial properties of triangular GNPs show better activity towards gram positive and gram-negative bacteria than spherical GNPs [18] The sharp-faced triangular nanoparticles, irrespective of their surface chemistry, size or compositions, can pierce the membranes of endosomes and translocate to the cytoplasm where they can be retained. These features make them preferable to round shaped nanoparticles for drug delivery, gene delivery, sub cellular targeting, and long-term tracking [23]. In a recent report GNPs of extreme small sizes i.e. less than $2 \mathrm{~nm}$ resulted in high antibacterial activity against gram positive as well as gram negetaive bacteria [1].

\section{Mechanism of antibacterial activity of gold nanoparticles}

The NPs are capable of attaching to the bacterial membrane by electrostatic interaction and disrupt its integrity [24]. They can change membrane potential and decrease ATP levels within the cell and inhibit the binding of tRNA with ribosomal subunit, affecting translation [25]. GNPs can generate holes in the cell wall causing leakage of cell contents, and bind with the DNA, inhibiting transcription [26]. GNPs aggregate within bacterial biofilms and bind to their surfaces causing cell wall distortions which can be utilized to minimize treatment durations and sideeffects of drugs [21]. Oxidative stress generated by free radical formation, that is, ROS, is triggered by nanotoxicity that leads to the death of bacterial cell [27] The interaction between ultrasmall GNPs (less than 2nm range) and bacteria likely induce a metabolic imbalance in bacterial cells resulting in an increase of intracellular ROS species production that culminated in death of the bacteria [1].

The possible use of GNPs in biomedical areas especially for cancer therapy has been a subject of research, owing to its possible toxic effects related to human exposure with its biomolecules, cells and tissues [28]. In humans it is known that the primary site of GNPs accumulation is the liver [29].

\section{Gold nanoparticles as vehicles of gene delivery}

Modification of GNP surfaces with bimolecular are often an integral step providing high gene transfer efficacy with minimal cytotoxicity [24]. The attractive features of GNPs in this regard include their surface plasmon resonance, controlled interaction with thiol groups, and their non-toxic nature [27]. GNPs functionalized with basic amino acid have been efficiently used as gene delivery vectors [30]. GNPs and protein conjugates provides excellent biocompatibility towards normal cells reducing nonspecific toxicity [31] GNPs are extensively exploited in organisms owing to its biocompatible nature, bioconjugation ability, strong absorbing and scattering properties [32], as target drug delivery in various therapeutics and cancer treatment. The rate of permeability and retention of nanoparticles are enhanced in cancerous cells than the normal cells by virtue of the accumulation and entrapment process which is the result of the leaky nature of tumor blood vasculature [32].

\section{How morphology of nanoparticles affect gene delivery capacity}

Morphology of nanoparticles could result in distinct biological properties within cellular systems [1]. In this report GNPs with two different morphology nanospheres and nanorods stabilized with BSA-PEI was to investigate the influence of the morphology on gene delivery. The rod-like complexes used their tips to contact and penetrate cells and had almost 100 -fold higher of transfection level than that of spherical complexes [1]. Moreover ultra small sizes of nanopsrticles (smaller than 1 nanometer) ensure homogeneous distribution of the nanoparticles throughout the cells which is comparable to proteins such as bovine serum albumin alone [33] Recently photoluminescent gold nanoclusters have garnered significant interest in biomedical research and applications owing to their ultrasmall size and unique molecule-like optical properties [33].

\section{Capping of gold nanoparticles as a means to enhance gene delivery}

Coating or capping of nanoparticles often ensures increase in biocompatibility and reduction of toxicity [33]. The capping of nanoparticles also ensures greater uptake and retention by cancer cells and other cells, which allowed greater time for integration of the delivered gene. Synthesis of vectors based on various cationic polymers such as polyethylenimine (PEI), polypropylenimine (PPI) and polyamidoamine (PAMAM) and their derivatives is utilized for transfer of plasmid DNA into human cell lines and treatment of genetic diseases [34]. The use of PEG (polyethylene glycol) is often used to functionalize GNPs as non-viral vectors in the transfection of different cell lines [35]. GNPs covalently coupled with polyethylene Polyethylenimine (PEI) can also be used as potent transfection reagents where expression levels of the transfereed gene are similar or greater than that obtained with commercially available lipoplexes [35]. In another study polyethyleneimine-g-bovine serum albumin (BSA-PEI) was used as non-viral gene vector resulting in good colloid stability and high transfection efficiency [36].

\section{Conclusion}

On the whole it can be said that GNPs have created immense interest in the field of medicine as an antimicrobial agent as well as vehicles of gene delivery. The assessment of the biocompatibility and potential toxicity of gold nanoclusters remains a major importance before their clinical application [33]. 


\section{Acknowledgement}

I acknowledge DBT, Government of India for partial funding of some of the work mentioned here that were published from our laboratory. Partial funding was also obtained from UGC CAS, India.

\section{References}

1. Zheng K, Setyawati MI, Leong DT, Xie J Antimicrobial gold nanoclusters. ACS Nano 11(7): 6904-6910.

2. Chowdhury S, Basu A, Kundu S (2014) Green synthesis of protein capped silver nanoparticles from phytopathogenic fungus Macrophomina phaseolina (tassi) goid with anti microbial properties against multi drug-resistant bacteria. Nano scale. Res Lett 9(1): 365

3. Liu C, Zhang N (2011) Nanoparticles in gene therapy: principles, prospects, and challenges. Prog Mol Biol Transl Sci 104: 509-562.

4. Dizaj SM, Jafari S, Khosroushahi AY (2014) A sight on the current nanoparticle-basedgene delivery vectors. Nanoscale Research Letters 9: 252.

5. Paciotti GF, Myer L, Weinreich D, Goia D, Pavel N, et al. (2004) Colloidal gold: anovel nanoparticle vector for tumor directed drug delivery. Drug Deliv 11(3): 169-183.

6. Podsiadlo P, Sinani VA, Bahng JH, Kam NWS, Lee J, et al. (2008) Gold nanoparticles enhance the anti-leukemiaaction of a 6-mercaptopurine chemotherapeutic agent. Langmuir 24(2): 568-574.

7. Ray S, Sarkar S, Kundu S (2011) Extracellular biosynthesis of silver nanoparticles using the mycorrhizal mushroom Tricholoma crassum (berk.) SACC: its antimicrobial activity against pathogenic bacteria and fungus, including multidrug resistant plant and human bacteria. Digest Journal of Nanomaterials and Biostructures 6(3): 1289-1299.

8. Bar H, Bhui DK, Sahoo GP, Sarkar P, Pyne S, et al. (2009) Green synthesis of silver nanoparticles using seed extract of Jatropha curcas. Colloids Surf: Physiochem Eng Aspects 348(1-3): 212-216.

9. Zhiruiguo S, Songzhang Y, Ninggu J (2007) Biosynthesis of Gold Nanoparticles Using the Bacteria Rhodopseudomonas capsulata. Materials Letters 61(18): 3984-3987.

10. Sastry M, Ahmad A, Islam Khan M, Kumar R (2003) Biosynthesis of metal nanoparticles using fungi and actinomycete. Current Science 85(2): 162-170.

11. Ramakrishna M, Rajesh Babu D, Gengan RM, Chandra S, Nageswara Rao G (2016) Green synthesis of gold nanoparticles using marine algae and evaluation of their catalytic activity. J Nanostruct Chem 6 : 1.

12. Mourato A, Gadanho M, Lino AR, Tenreiro R (2011) Biosynthesis of Crystalline Silver and Gold Nanoparticles by Extremophilic Yeasts. Bioinorganic Chemistry and Applications 2011: 8.

13. Bhainsa KC, D’Souza SF (2006) Extracellular biosynthesis of silver nanoparticles using the fungus Aspergillus fumigates. Colloids and Surfaces B: Biointerfaces 47(2): 160-164.

14. Sanghi R, Verma P, Puri S (2011) Enzymatic Formation of Gold Nanoparticles Using Phanerochaete chrysosporium. Advances in Chemical Engineering and Science 1: 154-162.

15. Ahmed S, Ikram S (2015) Synthesis of Gold Nanoparticles using Plant Extract: An Overview. Nano Res Appl 1: 1.

16. Noruzi M, Zare D, Davoodi D (2012) A rapid biosynthesis route for the preparationof gold nanoparticles by aqueous extract of cypress leaves at room temperature. Spectrochim Acta A: Mol Biomol Spectrosc 94: 84-88.
17. Singh R, Singh Nalwa H (2011) Medical Applications of Nanoparticles in Biological Imaging, Cell Labeling, Antimicrobial Agents, and Anticancer Nanodrugs. J Biomed Nanotechnol 7(4): 489-503.

18. SmithaSL, Gopchandran KG (2013) Surface enhanced Raman scattering, antibacterial and antifungal active triangular gold nanoparticles. Spectrochim Acta A Mol Biomol Spectrosc 102: 114-119.

19. Lima E, Guerra R, Lara V, Guzmán A (2013) Gold nanoparticles as efficient antimicrobialagents for Escherichia coli and Salmonella typhi. Chemistry Central Journal 7(1): 11.

20.Wani IA, Ahmad T (2013) Size and shape dependant antifungal activity of gold nanoparticles: A case study of Candida. Colloids Surf B Biointerfaces 101: 162-170.

21.Zawrah MF, Abd El-Moez SI (2011) Antimicrobial Activities of Gold Nanoparticles against Major Foodborne Pathogens. Life Science Journal 8(4): 37-44.

22. Bindhu MR, Umadevi M (2014) Antibacterial activities of green synthesized gold nanoparticles. Mater Lett 120: 122-125.

23. Chu Z, Zhang S, Zhang, Chunyuan B, Fang ZC, et al. (2014) Unambiguous observation of shapeeffects on cellular fate of nanoparticles. Scientific Reports 4: 4495.

24. Tiwari PK, Soo Lee Y (2013) Gene delivery in conjunction with gold nanoparticle and tumor treating electric field. J Appl Phys 114(5): 5.

25. Cui Y, Zhao Y, Tian Y, Zhang W, Lü X, et al. (2012) The molecular mechanism of action of bactericidal gold nanoparticles on Escherichia coli. Biomaterials 33(7): 2327-2333.

26. Rai A, Prabhune A, Perry CC (2010) Antibiotic mediated synthesis of gold nanoparticles with potent antimicrobial activity and their application in antimicrobial coatings. J Mater Chem 20: 6789-6798.

27. Dakrong P, Takuro N, Michael B (2011) The forthcoming applications of gold nanoparticles in drug and gene delivery systems. Journal of Controlled Release 149(1): 65-71.

28. Maurer-Jones MA, Bantz KC, Love SA, Marquis BJ, Haynes CL (2009) Toxicity of therapeutic nanoparticles. Nanomed 4(2): 219-241.

29. Sonavane G, Tomodaa K, Makinoa K (2008) Biodistribution of colloidal gold nanoparticles after intravenous administration: Effect of particle size. Colloids Surf B Biointerfaces 66(2): 274-280.

30. Ghosh PS, Kim C, Han G, Forbes NS, Vincent M, et al. (2008) Efficient Gene Delivery Vectors by Tuning the Surface ChargeDensity of Amino Acid-Functionalized Gold Nanoparticles. ACS Nano 2(11): 2213-2218.

31. Shukla R, Bansal V, Chaudhary M, Basu A, Bhonde RR, et al. (2005) Biocompatibility of gold nanoparticles and their endocytotic fate inside the cellular compartments microscopic overview. Langmuir 21(23): 10644-10654.

32. Bhattacharya R, Mukherjee P, (2008) Biological properties of 'naked' metal nanoparticles. Adv Drug Deliv Rev 60(11): 1289-1306.

33. Matulionyte M, Dapkute D, Budenaite L, Jarockyte G, Rotomskis R (2017) Photoluminescent gold nanoclusters in cancer cells: cellular uptake, toxicity, and generation of reactive oxygen species. Int J Mol Sci 18(2): E378.

34. Teimouri M, Nia AH, Abnous K, Eshghi H, Ramezani M (2016) Graphene oxide-cationic polymer conjugates: synthesis and application as gene deliveryvectors. Plasmid 84-85: 51-60.

35. Mar Encabo-Berzosa M, Sancho-Albero M, Sebastian V, Irusta S, Arruebo M, et al. (2017) Polymer functionalized gold nanoparticles as non-viral gene delivery reagents. J Gene Med 19(6-7).

36. Zhang P, Li B, Du J, Wang Y (2017) Regulation the morphology of cationized gold nanoparticles for effective gene delivery. Colloids Surf B Biointerfaces 28(157): 18-25. 

(C) Commons Attribution 4.0 Licens (c) DOI: 10.19080/AIBM.2017.04.555658
Your next submission with Juniper Publishers will reach you the below assets

- Quality Editorial service

- Swift Peer Review

- Reprints availability

- E-prints Service

- Manuscript Podcast for convenient understanding

- Global attainment for your research

- Manuscript accessibility in different formats

( Pdf, E-pub, Full Text, Audio)

- Unceasing customer service

Track the below URL for one-step submission https://juniperpublishers.com/online-submission.php 